\title{
USB 2.0 Digital Camera Characterization for Optimizing the Making of High Power RGB-LED Fluorescence Imaging System
}

\author{
Atika Apriani ${ }^{1} *$, Rochan Rifai ${ }^{2}$, Frida Agung Rakhmadi ${ }^{1}$, Khamidinal ${ }^{3}$ \\ ${ }^{1}$ Physics Department, ${ }^{3}$ Chemistry Education Department, Faculty of Science and Technology, UIN Sunan Kalijaga, \\ Jl. Marsda Adisucipto No 1 Yogyakarta 55281, Indonesia. Tel. +62-274-540971, Fax. +62-274-519739. \\ ${ }_{2}^{2}$ PT. Madeena Karya Indonesia, Dusun Sambisari RT/RW:03/02 Desa Purwomartani Kec Kalasan Kab Sleman. \\ Email*: aprianiatika713@gmail.com
}

\begin{abstract}
This research aims to obtain the focal length and radial and tangential distortion of a USB 2.0 digital camera. This research was conducted in three stages namely preparation of tools and materials, camera characterization, and data processing. The tools used in this study include a USB 2.0 digital camera and MATLAB R2013a software, while the object is a collimator board. Characterization of digital cameras is done through data collection with a distance variation of $3 \mathrm{~cm}$ until $15 \mathrm{~cm}$, then the data obtained is processed using MATLAB R2013a software to obtain the focal length and radial distortion and tangential distortion values. The USB camera that used has the characteristic focal length and radial distortion and certain tangential distortion for each distance.
\end{abstract}

Keywords: Characterization, USB 2.0 Digital Camera, Focal Length, Radial and Tangential Distortion.

\section{INTRODUCTION}

Fluorescence is an atomic or molecular phenomenon that absorbs energy with certain wavelengths and causes the transition of quantum states from low energy to high energy levels which then emits light with energy lower than absorption energy (Lee et al., 2018, p. 533). Fluorescence uses an excitation source in the form of LED with a specific wavelength that matches the sample to be used. One of the LEDs which has a higher intensity intensity character than ordinary LED is High Power RGB-LED. High Power emits three colors namely red, green and blue.

Fluorescence imaging is one of the optical methods used in food classification that is able to support the authentication of food halality. This method was developed because it is simple, non-destructive or nondestructive, high sensitivity, cheap, and fast (Sankaran et al., 2010, p. 4). This system requires a USB 2.0 camera to record the effects of fluorescence on samples that have been exposed to light. The USB 2.0 camera used needs to be characterized in advance so that it knows or can estimate the distance between the camera and the sample place. By doing camera characterization, it will produce better fluorescence image results and have a high level of stability. This characterization process will also optimize the performance of the fluorescence imaging system. The results of the camera characterization carried out obtained values of focal length and radial distortion and tangential distortion.

\section{MATERIALS AND METODS}

\section{Tools and Materials}

There are several tools and materials that must be prepared during the camera characterization process. Tools and materials used are USB cameras, laptop, collimator board and MATLAB R2013a software.

\section{Work Procedures}

Characterization of the camera is done through four stages, namely preparation of tools and materials, assembling tools, data retrieval, data processing. The four stages are explained in detail as follows.

1. In the first stage is preparing tools and materials aimed at preparing all types of tools and materials such as laptops, collimator boards, and MATLAB R2013a software. Preparation of tools and materials made before the camera characterization process can provide effectiveness and time efficiency.

2. The second step is assembling the device. This stage has a target that is a series of tools that will be used in the process of capturing camera characterization data. The circuit is arranged by meansof a collimator board mounted perpendicular to the USB Camera with the specified distance variation. Where the USB Camera is connected with MATLAB R2013a software.

3. The third stage is data collection. The purpose of this stage is to process the data to be characterized. The target of this stage is in the form of image data from a collimator board which is used as an object when shooting pictures of the camera. The process of collecting data was carried out nine times with the specified distance variation of $3-15 \mathrm{~cm}$. The data 
that has been obtained will then be entered into the Calib Toolbox folder.

4. The last step is data processing. The purpose of this stage is to find out the results of the characteristics of the camera used. Characterization results obtained are the value of the focal length and radial distortion and tangesial distortion. With the known characterization results, it will optimize the performance of the fluorescence imaging system.

\section{RESULTS AND DISCUSSION}

Characterization of the camera has been successfully carried out using the laboratory calibration method with the overall results obtained as shown in Table 1. The results of the characterization obtained were the focal length values as well as radial distortion and tangential distortion.

Table 1. The camera characterization results.

\begin{tabular}{|c|c|c|c|c|c|c|}
\hline \multirow{3}{*}{$\begin{array}{c}\text { Variasi } \\
\text { Jarak } \\
\text { (cm) }\end{array}$} & \multirow{2}{*}{\multicolumn{2}{|c|}{ Panjang Fokus }} & \multicolumn{4}{|c|}{ Distorsi } \\
\hline & & & \multicolumn{2}{|c|}{ Radial } & \multicolumn{2}{|c|}{ Tangensial } \\
\hline & $\mathrm{fx}$ & fy & $\mathrm{x}$ & $y$ & $x$ & $y$ \\
\hline 3 & 2387.85 & 2601.51 & -0.8122 & -15.04 & -0.01121 & 0.00711 \\
\hline 4 & 10321.7 & 9319.61 & -37.36 & -2244 & 1.045 & 0.4915 \\
\hline 5 & 7221.35 & 3834.59 & -7.14 & -91.26 & -0.04171 & 0.4253 \\
\hline 6 & 7251.35 & 3894.56 & -7.23 & -91.50 & -0.04171 & 0.4253 \\
\hline 7 & 12911.3 & 5781.14 & -3.956 & -2151 & 0.07319 & -0.06809 \\
\hline 8 & 1179.37 & 2610.73 & -1.171 & -8.583 & -0.03762 & -0.04921 \\
\hline 9 & 3012.84 & 3110.97 & -23.22 & -681.3 & -0.4887 & -0.4806 \\
\hline 10 & 13895.1 & 14462 & -19.3 & -1.269 & -0.3206 & 0.05203 \\
\hline 11 & 4145.84 & 4355.99 & -9.687 & -480.8 & -0.06533 & 0.2987 \\
\hline 12 & 60950 & 62132.1 & -949.7 & -1.668 & -0.2533 & 0.4503 \\
\hline 13 & 2698.84 & 2862.8 & -0.9547 & -164.7 & -0.02823 & -0.174 \\
\hline 14 & 754.838 & 784.568 & -0.04772 & -0.1376 & 0.004701 & 0.006914 \\
\hline 15 & 4383.39 & 4511.16 & -2.528 & -1691 & -0.0235 & -0.1225 \\
\hline
\end{tabular}

\section{Focal Length}

The focal length is the perpendicular distance between the center of the lens and the projection plane of the camera (Aristia, 2014, p. 15). As has been shown by Table 4.1 that the focal length of the camera at a distance of $3 \mathrm{~cm}$ is fx of 2387.85 and fy of 2601.51 . The value of the focal length that has been obtained indicates that the image obtained has two focal length values namely on the $\mathrm{x}$ axis and $\mathrm{y}$ axis. This gives information that the image has a $2 \mathrm{D}$ form. The explanation also applies to the results of the focal length at variations in the distance of $5 \mathrm{~cm}$ to $15 \mathrm{~cm}$.

The focal length information from the camera as shown in Table 4.1 can be used to determine the ideal distance between the camera and the sample place. Placing the camera at the ideal distance will optimize the performance of high-power RGB-LED fluorescence imaging systems.

\section{Radial Distortion}

Radial distortion is a linear shift of photo points in the radial direction with respect to the main point from its ideal position (Aristia, 2014, p. 16). As with the focal length value, the radial distortion value is also shown in Table 4.1. Based on Table 4.1, information is obtained that the radial distortion value of the camera at a distance of $3 \mathrm{~cm}$ is -0.8122 on the $\mathrm{x}$-axis and -15.04 on the $\mathrm{y}$-axis. Radial distortion values that have been obtained indicate that the camera to be used has negative radial distortion or barrel distortion. This provides information that the sides of the image that were originally square shaped curved outwardly away from the center of the image. The explanation also applies to the results of radial distortion at variations in the distance of $5 \mathrm{~cm}$ to $15 \mathrm{~cm}$.

\section{Tangential Distortion}

Tangential distortion is a linear shift of a point in a photo in the normal direction (perpendicular) to a radial line through the photo point (Aristia, 2014, p. 17). As with radial distortion values, tangential distortion values are also shown in Table 4.1. Based on Table 4.1, information is obtained that the results of the camera shooting that will be used in this study have a hyperbolic impression that the lens elements in the combined lens experience excessive impression. The explanation also applies to the results of tangential distortion at variations in the distance of $5 \mathrm{~cm}$ to $15 \mathrm{~cm}$.

The results of radial and tangential distortion values that have been obtained function in analyzing the results of the obtained fluorescence images. By knowing this value, it can be analyzed the image obtained so that the image results are not much wasted because of distortion in the camera used. This can produce a better image and has a high level of stability in the fluorescence image obtained.

\section{ACKNOWLEDGEMENTS}

Thank you to Rochan Rifai, Mr. Frida Agung Rakhmadi and Mr. Khamidinal for providing the knowledge and ideas for this research. I also thank Mr. Frida Agung Rakhmadi and Mr. Khamidinal for their guidance.

\section{CONCLUSION}

The results of radial and tangential distortion values that have been obtained function in analyzing the results of the obtained fluorescence images. By knowing this value, it can be analyzed the image obtained so that the image results are not much wasted because of distortion in the camera used. This can produce a better image and has a high level of stability in the fluorescence image obtained. 


\section{REFERENCES}

Aristia, N. (2014). Pemodelan 3D Kawasan Cagar Budaya Menggunakan Fotogrametri Jarak Dekat Kombinasi Data Foto Teretris dan Foto Udara (Studi Kasus Kawasan Candi Sambisari-Yogyakarta). Universitas Gadjah Mada Yogyakarta.

Lee, H., Kim, M. S., Lee, W., \& Cho, B. (2018). Sensors and Actuators B: Chemical Determination of the total volatile basic nitrogen (TVB-N) content in pork meat using hyperspectral fluorescence imaging. Sensors \& Actuators: B. Chemical, 259, 532-539. https://doi.org/10.1016/j.snb.2017.12.102.

Sankaran, S., Mishra, A., Ehsani, R., \& Davis, C. (2010). A review of advanced techniques for detecting plant diseases. Computers and Electronics in Agriculture, 72(1), 1-13. https://doi.org/10.1016/j.compag.2010.02.007 
THIS PAGE INTENTIONALLY LEFT BLANK 